\title{
Introduction to the HICSS-55 Minitrack on GIS, Industry 4.0, and Sustainability
}

\author{
Namchul Shin \\ Pace University \\ nshin@pace.edu
}

\section{Introduction to Minitrack}

This minitrack aims to provide a research forum by presenting scholarly research papers that discuss the varied facets of Geographic Information Systems (GIS) for Industry 4.0 and sustainability. The fourth Industrial Revolution is characterized by emerging technologies, such as AI, machine learning, IoT, blockchain, and the Cloud, which can improve economic conditions and reduce negative societal impacts. Industry trends increasingly focus on sustainable business practices, responsiveness to climate change, and related social and environmental issues. GIS (or location analytics) is one of the key technologies of Industry 4.0. Location data and spatial features embedded in such emerging technologies often facilitate and accelerate technological advancements by integrating people, processes, things, cities, societies, and environments into one ecological system, which are bound to create not just extensive opportunities for economic gains, but also a positive externality of ecological sustainability.

\section{Paper Presentation}

The paper, "Utilizing Geographic Information Systems for Condition-Based Maintenance on the Energy Distribution Grid," by P. Heiden, J. Priefer, and D. Beverungen, designs a system for condition-based maintenance of legacy assets on the energy distribution grid, which can prevent energy outage and reduce resource consumption by utilizing geospatial data of these assets with location analytics and GIS. While extant research has presented algorithms for condition-based maintenance, no design knowledge is available to prescribe how a system for this purpose should be designed. This research aligns with the design science research paradigm and follows the design science research model as proposed by Peffers, et al. (2008). It fosters new research on GIS by showing how to integrate machine learning and location analytics of immobile objects like electric substations to build efficient and effective systems for condition monitoring and conceptualize how this type of work depends on GIS. The designed system for condition-based maintenance on the energy distribution grid can be applied for other cases of

\author{
Dan Farkas \\ Pace University \\ dfarkas@pace.edu
}

geographically distributed assets, which are either immobile, e.g., wind turbines, heating and air-condition systems, or mobile, e.g., cars.

\section{Conclusion}

This is the first year this minitrack is included in the Location Intelligence Track at the HICSS. The minitrack accepted only one paper. However, as the importance of integration of GIS, AI, IoT, and Cloud Computing increases, we expect more research be conducted in this area and look forward to receiving more research papers at the HICSS in 2023.

The paper included in the minitrack adds to the existing knowledge and practice of location analytics and intelligence in the system sciences. It also suggests there is limited knowledge in this area, which needs to be addressed and discovered by future research.

\section{Reference}

K. Peffers, T. Tuunanen, M. A. Rothenberger, and S. Chatterjee, "A Design Science Research Methodology for Information Systems Research," Journal of MIS, vol. 24, no. 3, pp. 45-77, 2008. 